\title{
当代企业与职工双向沟通影响因素分析及对策研究
}

\author{
张晓晴 王树武 王军 \\ 山东龙口烟台南山学院商学院 \\ DOI:10.32629/jief.v2i2.638
}

[摘 要] 当今社会人员流动频繁, 企业对沟通机制相对忽视, 导致员工沟通障碍日益严重, 降低企业运行效率。文章以当代企业与职工为研 究对象, 探究双向沟通的影响因素, 并提出相应解决对策, 为企业解决与职工双向沟通问题提供一定参考价值。

[关键词]企业与职工; 双向沟通; 影响因素

\section{1 当代企业与职工沟通现状分析}

随着时代的变迁, 岁月的更替, 沟通已经成为当代人群生活不可缺 少的一部分; 而工作是人们维持正常生活的重要一环, 因此, 在工作中 进行有效沟通有利于促进人类高效发展, 双向沟通是满足有效沟通的重 要工具之一。

1.1 没有灵活的沟通制度

许多企业在都曾表明过进行有效沟通的重要性, 能够与沟通相关联 的制度不多, 且现行制度几乎都是围绕信息发布展开, 缺乏灵活的沟通 制度, 对于内部也没有建立起相应的监督机制, 使职工形成沟通是管理 层向职工下达指令单向沟通的意识, 大部分职工有时不明白或有问题也 很少向上级提问, 形成一种单向沟通机制, 死板且不灵活。

\section{2 没有良好的沟通渠道}

当代企业惯于采用链式管理, 尤其是管理层以下岗位, 部分想法特 例的职工有想法向上级禀报, 一种可能禀报完没下文, 并且受到指责, 另一种可能就是被上级盗取想法向上邀功, 毕竟处于下风的职工是无法 反驳的, 造成职工缺乏对企业的归属感。

1.3 职工缺乏沟通技能

当代职工大多独生子女, 从小处于父母的呵护下, 缺乏沟通的历练, 较弱的倾听能力。运用的沟通方式多为语言沟通, 导致部分信息缺失, 无法进行保存。此外, 职工在沟通时时常表意不清, 缺乏清晰的叙述能 力; 谈话中没有明确主张, 不会表达自己的观点; 表达时时常主次不分, 不能够开门见山的讲述重点; 不会倾听, 总是固持己见的否定他人等。 沟通贯穿于企业的始终, 无论是职工间紧密配合, 还是部门间的合作, 良好的沟通能力是企业职工需要具备的基本技能, 也是决定其未来成功 的必要条件。

\section{2 当代企业与职工双向沟通影响因素分析}

2.1 环境因素

(1) 沟通氛围: 当代绝大多数企业都把自己定位在权威者或者是掌 控者的位置, 在某些时候无法和员工进行有效的双向沟通, 因此在企业 的改革和内部调整的时候, 很多的基层员工并不了解企业的发展方向和 管理模式, 造成员工的凝聚力不强、没有上进心、没有目标的结果, 严 重影响了整个企业今后的发展。在当代企业的管理和发展过程中, 缺乏 良好的沟通氛围, 积极主动地与职工去进行合理的双向沟通有助于提升 企业自身的竞争优势。

（2）组织结构: 如今企业为了能更长久发展, 大多设置组织机构是 层级既复杂又过多, 信息进行传递时间长, 影响信息传递的及时性更别 提设置反馈机制, 在中间职工进行编码一解码一编码过程中信息早已失 真, 不利于企业与职工进行及时的双向沟通。

2.2 个人因素

由于每个人的性格、思维方式、教育等差异化, 即使接收到的信息
相同, 但在其接收时会有不自觉的选择忽略性, 每个人的关注点不同, 对事物、事件的认知程度不同, 造成上层领导发送信息之后, 得到反馈 的信息并不是最优的甚至与期望回答相悖。无效的双向沟通就由此产生, 甚至会严重影响日常工作进程。

\section{3 企业与职工双向沟通问题的解决对策}

3.1 提高企业的沟通氛围

所谓的企业沟通实际上就是领导者与职工进行工作上的交流, 使企 业了解职工的想法, 职工明白企业的理念, 而良好的双向沟通和公司的 氛围及环境是一定分不开的, 企业要是想提高与职工间的沟通效率, 就 必须营造一个自由、平等、真诚、平和、尊重的沟通氛围, 使职工在这 种良好的沟通环境之下, 建立与企业的安全感、责任感, 从而转变他们 的立场, 思考的角度, 对工作的态度、对企业的责任感等。

3.2 调整组织架构

一般情况下, 组织结构层级越多, 就会降低信息传递的速度, 信息 接触到的人越多, 信息失真的概率越大, 但层级过少, 会导致组织结构 不稳定, 管理难度增大, 降低职工工作积极性等情况。因此, 要以组织 架构的稳定性存在为前提, 对办事层级进行适当的缩减, 来提高信息传 播的速度, 减少信息失真的状况。并在现有基础上改进不协调的组织关 系, 做到分工清晰, 人岗匹配, 提供职工良好的发展空间。

3.3 提高职工沟通技能

首先, 职工要对自己有一个明确的认识。明确了自己各方面的情况 之后, 选择一定的策略进行之后的沟通; 然后就是职工在沟通的时候要 懂得换位思考。要和别人沟通必然离不开和自己的沟通, 通过换位思考, 那么就会更容易让对方接受自己在本次沟通过程中所要传达的信息, 使 得此次沟通的过程更加的有效; 之后就是对于反馈应引起重视。只有在 反馈的帮助下才能及时的知道此次的沟通达到的结果和预期到底有多大 的差距, 这样对此次沟通有一定的促进作用; 最后就是要彼此倾听。在 沟通的过程中, 做一个积极的倾听者能够在很大程度上克服掉自己的失 误, 使此次沟通过程更加的有效。

\section{[参考文献]}

[1]曹修涵,徐建国.中小企业内部沟通现状、影响因素及对策研究 [J]. 中国市场,2017(22):170-171,176.

[2]王丽. 现代企业内部管理沟通问题及对策 [J]. 管理创 新,2017(34):24-25.

[3] 宋占新. 组织内部管理沟通的障碍及消除 [J]. 领导科 学,2015(24):25-27.

作者简介: 张晓晴 (1997-), 女, 天津, 工商管理专业在读本 科; 王树武 (1984-), 男, 内蒙古商都人, 讲师, 研究方向: 人力 资源管理; 王军 (1985-), 男, 山东济南人, 南山控股集团宣传部 部长, 讲师, 研究方向: 人力资源管理、思想政治教育。 